\title{
Hybridization Studies by Crossing and Protoplast Fusion within the Genus Schizosaccharomyces Lindner
}

\author{
By MÁTYÁS SIPICZKI I ${ }^{*}$, JUDIT KUCSERA ${ }^{1}$, \\ STANISLAW ULASZEWSK I ${ }^{2}$ AND JÁNOS ZSOLT ${ }^{1}$ \\ ${ }^{1}$ Department of Microbiology, Attila József University, H-6701 Szeged, P.O. Box 428, Hungary \\ ${ }^{2}$ Microbiological Institute, Wroctaw University, 51-148 Wroctaw, Poland
}

(Received 2 November 1981; revised 6 February 1982)

\begin{abstract}
Hybridization studies based on the use of crossing and the protoplast fusion technique revealed the relationship between the various taxa of the yeast genus Schizosaccharomyces Lindner. From a series of intra- and interspecific crosses as well as protoplast fusions, we concluded that a revision of the genus is required. Being interfertile, $S$. pombe and $S$. malidevorans have to be included in one species $S$. pombe. From the protoplast fusion results, this new taxon seems to be closely related to $S$. octosporus. The results obtained are discussed in connection with the characteristics of the low temperature spectra of the cytochromes.
\end{abstract}

\section{INTRODUCTION}

Yeast taxonomy which is based almost exclusively on physiological and morphological characteristics (for details, see Lodder, 1970) does not reveal real evolutionary relationships between the various taxa. In many cases the criteria used to differentiate yeast species reflect only small genetic differences rather than a true species delineation (Stahl \& Esser, 1979). The shortcomings of the classification criteria have recently resulted in the revival of interfertility, introduced by Winge \& Laustsen (1939) as a criterion for conspecificity. It has fruitfully been used in the delimitation of species in a number of ascomycetous genera, for instance Hansenula (Wickerham, 1970), Saccharomyces (Winge \& Laustsen, 1939; Neumann, 1972) and Klulteromyces (Johannsen \& van der Walt, 1978; Johannsen, 1980). Johannsen (1981) recently reported hybridization studies within the genus Schizosaccharomyces Lindner, but failed to detect interfertility between the species.

The purpose of our report is to present further data concerning interfertility within the genus Schizosaccharomyces, and to introduce the protoplast fusion technique in studies on the relatedness between the species. According to Sloof (1970), the genus contains four species, including two varieties, which can be distinguished on the basis of some morphological properties and their different abilities to utilize three sugars (maltose, raffinose and melibiose). Later, an additional species was described by Kumbhojkar (1972), who found that two strains of the Centraalbureau voor Schimmelcultures (CBS) previously thought to be $S$. octosporus Beijerinck do not ferment maltose and can therefore be considered as comprising a new species. He suggested the name $S$. sloofi for this taxon. Although our studies have been restricted to the four species previously described (Sloof, 1970), it can nevertheless be concluded that the genus must be reconsidered. Since all of the four species possess marked sexuality (Lindner, 1893; Beijerinck, 1894; Wickerham \& Duprat, 1945; Leupold, 1950; Suminoe \& Dukmo, 1963; Rankine \& Fornachon, 1964), hybrids can be formed within any species. This provides a possibility of demonstrating interfertility between the phenotypically delimited species, as attempted by Johannsen (1981). In contrast to her findings we have observed that $S$. pombe and $S$. malidevorans can be hybridized, and recombination also occurs between the two genomes. From a series of intra- and interspecific crosses as well as protoplast fusions, we concluded that $S$. pombe and 
$S$. malidevorans in all probability constitute one common species and are closely related to $S$. octosporus.

\section{METHODS}

Strains. The Schizosaccharomyces strains used in this study are listed in Table 1. All species except S. pombe Lindner originated from the Czechoslovak Collection of Yeasts (CCY) in Bratislava. The genetically marked strains of $S$. pombe were obtained from the Institute of General Microbiology of the University of Bern (Switzerland) or from the Institute of Genetics of the University of Munich (F.R.G.). Saccharomyces cerevisiae DP1-1D originated from the Microbiological Institute of Wroclaw University (Poland).

Media. YEL, YEA, MEA, MMA and MMAK were described previously (Sipiczki \& Ferenczy, 1977). YEL contained $0.5 \%(\mathrm{w} / \mathrm{v})$ yeast extract and $1 \%(\mathrm{w} / \mathrm{v})$ glucose. YEA was YEL supplemented with $2 \%$ Bacto-agar (Difco). MEA contained 3\% (w/v) malt extract and 2\%(w/v) Bacto-agar. MMA was synthetic minimal medium containing $1 \%$ (w/v) glucose, $2 \%$ Bacto-agar, $0.5 \%(\mathrm{w} / \mathrm{v})\left(\mathrm{NH}_{4}\right)_{2} \mathrm{SO}_{4}, 0.01 \%(\mathrm{w} / \mathrm{v}) \mathrm{KH}_{2} \mathrm{PO}_{4}, 0.005 \%(\mathrm{w} / \mathrm{v}) \mathrm{MgSO}_{4}$ and vitamins according to van der Walt (1970). Where the experiment required this, the MMA was supplemented with amino acids and bases, each at $50 \mu \mathrm{g} \mathrm{ml}^{-1}$. MMAK was MMA supplemented to contain $0.6 \mathrm{M}-\mathrm{KCl}$. SPA was synthetic sporulation medium, containing $1 \%(\mathrm{w} / \mathrm{v})$ glucose, $0.1 \%(\mathrm{w} / \mathrm{v}) \mathrm{KH}_{2} \mathrm{PO}_{4}$ and vitamins as in MMA (Leupold, 1970). GCM was glycerol complete medium containing $0.5 \%(\mathrm{w} / \mathrm{v})$ yeast extract, $3 \%(\mathrm{v} / \mathrm{v})$ glycerol and $2 \%(\mathrm{w} / \mathrm{v})$ Bacto-agar (Wolf et al., 1971). Drug media were prepared by adding ethanolic solutions of erythromycin (Antibiotika Fabrik, Jasi) and diuron (Riedel-De Haen AG) in final concentrations of $6 \mathrm{mg} \mathrm{ml}^{-1}$ and $0.01 \mathrm{mg}$ $\mathrm{ml}^{-1}$, respectively, to GCM at $40{ }^{\circ} \mathrm{C}$. YPG contained $1 \%(\mathrm{w} / \mathrm{v})$ yeast extract, $1 \%(\mathrm{w} / \mathrm{v})$ Bacto-peptone, $2 \%(\mathrm{w} / \mathrm{v})$ glucose and $2 \%(w / v)$ Bacto-agar.

Table 1. Species and strains of Schizosaccharomyces used in this study

Organism

1. Schizosaccharomyces octosporus Beijerinck CCY 44-2-1 (CBS 1804)

2. Schizosaccharomyces octosporus Beijerinck met-105

3. Schizosaccharomyces octosporus Beijerinck ade-110

4. Schizosaccharomyces japonicus var. japonicus Yukawa et Maki CCY 44-5-1 (CBS 354)

5. Schizosaccharomyces japonicus var. japonicus Yukawa et Maki ura-106

6. Schizosaccharomyces japonicus var. japonicus Yukawa et Maki ura-110

7. Schizosaccharomyces japonicus var. versatilis (Wickerham et Duprat) Sloof CCY 44-3-1 (ATCC 9987)

8. Schizosaccharomyces japonicus var, versatilis (Wickerham et Duprat) Sloof lys-103

9. Schizosaccharomyces japonicus var. versatilis (Wickerham et Duprat) Sloof glu-126

10. Schizosaccharomyces malidevorans Rankine et Fornachon CCY 44-6-1 (CBS 5557)

11. Schizosaccharomyces malidevorans Rankine et Fornachon ura-103

12. Schizosaccharomyces malidevorans Rankine et Fornachon arg-121

13. Schizosaccharomyces pombe Lindner his7-366 $h^{-}$

14. Schizosaccharomyces pombe Lindner his7-366 $h^{+}$

15. Schizosaccharomyces pombe Lindner leu2-120 $h^{+}$

16. Schizosaccharomyces pombe Lindner his7-366 arg-1 leu2-120 $\mathrm{h}^{-}$

17. Schizosaccharomyces pombe Lindner ura5-294 $h^{-}$

18. Schizosaccharomyces pombe Lindner lys4-95 diu' -301 ery ${ }^{\mathrm{r}}-100 \mathrm{~h}^{-}$

19. Schizosaccharomyces pombe Lindner arg-1 diur $-122 \mathrm{~h}^{-}$
Origin of culture

CCY

This study; UV-induced mutant from 1.

This study; UV-induced mutant from 1 .

CCY

This study; UV-induced mutant from 4.

This study; UV-induced mutant from 4.

CCY

This study; UV-induced mutant from 7 .

This study; UV-induced mutant from 7 . CCY

This study; UV-induced mutant from 10 .

This study; UV-induced mutant from 10 .

UB

UB

UB

This study; haploid spore from crosses between 13,15 and 19

UB

UM

UM

Sources: CCY, Czechoslovak Collection of Yeasts, Bratislava, Czechoslovakia; CBS, Centraalbureau voor Schimmelcultures, Delft, The Netherlands; ATCC, American Type Culture Collection, Washington, D.C., U.S.A.; UB, Institute of General Microbiology, University of Bern, Switzerland; UM, Institute of Genetics, University of Munich, F.R.G. 
Mutant induction and characterization. UV mutagenesis, enrichment and isolation of auxotrophic mutants and determination of the auxotrophic characters were as described previously for $S$. pombe (Sipiczki \& Ferenczy, 1978).

Hybridization by crossing. Sexual hybridization of strains was achieved by the procedure of Wickerham \& Burton (1956) with slight modifications. Auxotrophic parents were mass-mated on MEA slants. After 1 week at $30^{\circ} \mathrm{C}$, the growth from the slants was taken up in sterile tap-water, washed three times by centrifugation and resuspended in $1.0 \mathrm{ml}$ sterile tap-water. For estimation of the total number of cells and the frequency of prototrophic hybrids and/or recombinants, samples were taken from the suspension, diluted and spread on to YEA and MMA plates. The plates were incubated at $30^{\circ} \mathrm{C}$ and the colonies were counted after $10 \mathrm{~d}$. Samples $(0 \cdot 5$ $\mathrm{ml}$ ) of the suspension were transferred on to fresh MEA slants. The whole procedure was then serially repeated at 7 $\mathrm{d}$ intervals over a period of 4 weeks. In order to detect the possible back-mutations, similar culturing of each auxotrophic parent strain was carried out in parallel with the crosses.

Hybridization by protoplast fusion. Protoplasts from the auxotrophic strains were prepared using Trichoderma enzyme. The methods of enzyme production and protoplast formation were similar to those described in a previous paper (Sipiczki, 1979). Fusion was induced using polyethylene glycol (PEG, mol. wt 4000) as for S. pombe (Sipiczki \& Ferenczy, 1977).

Genetic analysis of hybrids. Random spore analysis and tetrad analysis were performed according to Leupold (1970). For studies on the transmission and recombination of mitochondrial markers, the methods of Seitz-Mayr et al. (1978) were used with slight modifications. As all $S$. malidevorans mutants isolated in this study were of a mating type resembling the $h^{+}$type of $S$. pombe, the favourable features of meil-102 could not be exploited in the production of stable diploids. Therefore, each $S$. malidevorans strain was mixed with a $S$. pombe mutant of type $h^{-}$ instead of meil-102. The mixed suspension was then pipetted on to the surface of SPA and incubated at $25^{\circ} \mathrm{C}$ to allow zygote formation. On SPA, which does not contain any nitrogen source, no vegetative growth occurs, but the cells of opposite mating types copulate if they are in direct contact. After 18-24 h the mating mixture was suspended in sterile tap-water and plated on to MMA. The plates were incubated at $30^{\circ} \mathrm{C}$ for $4 \mathrm{~d}$ and the colonies with cell morphology resembling the diploid cell shape of $S$. pombe were picked off and suspended separately in sterile tap-water. Samples were then taken from these suspensions, diluted, spread on to MMA plates and incubated to allow colony formation. After $4 \mathrm{~d}$ the colonies were replica-plated on to GCM plates supplemented with the respective drugs.

Cytochrome absorption spectra. The cytochrome absorption spectra of intact cells harvested from YPG plates grown at $28{ }^{\circ} \mathrm{C}$ were determined on a cell paste. The cells were scraped off the plates, reduced by mixing with powdered $\mathrm{Na}_{2} \mathrm{~S}_{2} \mathrm{O}_{4}$, pressed into specially prepared cuvettes giving a final cell paste thickness of $1 \mathrm{~mm}$, and chilled in liquid nitrogen. The spectra were produced with a recording spectrophotometer Specord UV-vis (Carl Zeiss, Jena), using parafilm ' $M$ ' (American Can Company) as a reference blank.

Sugar fermentation test. Fermentative utilization of maltose was tested according to van der Walt (1970).

\section{RESULTS}

\section{Mutants}

From each species and variety (except $S$. pombe) auxotrophic mutants were isolated by UV treatment and subsequent enrichment by snail enzyme, and tested for reversion. All strains with a genetic reversion rate higher than $10^{-9}$ were discarded. Two of the stable ones were then chosen from every Schizosaccharomyces for crosses and fusion experiment. The $S$. pombe mutants used either originated from genetic collections (see Table 1) or were isolated as haploid spores from their crosses.

\section{Intraspecific crosses}

Prototrophic colonies appeared in all intraspecific crosses (Table 2), including those between the varieties of $S$. japonicus. Most of them had a lower sporulating ability than that of the original wild-type strains. As expected, in $S$. pombe the frequency of prototrophs was much higher when strains of different mating types were crossed than when two $h^{-}$strains were mass-mated. The appearance of prototrophs in the latter case could be a consequence of the instability of mating characters occasionally emerging in heterothallic strains (Egel, 1976). In $S$. malidevorans and $S$. pombe an increased cell size was peculiar to about $10 \%$ of the prototrophic colonies, which led us to believe that they are diploid hybrids produced from zygotes by vegetative growth, for in $S$. pombe diploid and polyploid cells are known to be systematically larger than haploid cells (Leupold, 1956). The colonies with normal cell size presumably resulted from recombinant 
Table 2. Intra- and interspecific crosses between auxotrophic mutants of Schizosaccharomyces

Crosses were carried out as described in Methods. The number of viable cells was determined by plating after crossing. Counts of prototrophs were determined by plating on to MMA plates.

$$
10^{-7} \times
$$

Parental strains

Number of viable Frequency of cells scored prototrophs

$S$. pombe his7-366 $h^{-} \times S$. pombe leu2-120 $h^{+}$

$S$. pombe his7-366 $h^{-} \times S$. pombe ura5-294 $h^{-}$

$S$. malidevorans ura-103 $\times S$. malidevorans arg-121

$S$. octosporus met-105 $\times S$. octosporus ade-110

$S$. japonicus var. japonicus ura-106 $\times$ S. japonicus var. japonicus ura-110

$S$. japonicus var. versatilis lys-103 $\times$ S. japonicus var. versatilis glu-126

$60 \cdot 7$

$30 \cdot 0$

$8 \cdot 2$

$11 \cdot 3$

$S$. pombe his7-366 $h^{-} \times S$. malidevorans ura-103

$S$. pombe his7-366 $h^{-} \times S$. malidevorans arg-121

$S$. pombe his7-366 $h^{+} \times S$. malidevorans ura-103

$S$. pombe his7-366 $h^{+} \times S$. malidevorans arg-12I

$S$. pombe his7-366 $h^{-} \times S$. octosporus met-105

$S$. pombe his $7-366 h^{-} \times S$. octosporus ade-110

$S$. pombe his $7-366 h^{+} \times S$. octosporus met-105

$S$. pombe his7-366 $h^{+} \times S$. octosporus ade-110

$S$. pombe his7-366 $h^{-} \times S$. japonicus var. japonicus ura-106

$S$. pombe his7-366 $h^{-} \times S$. japonicus var. japonicus ura-110

$S$. pombe his7-366 $h^{+} \times S$. japonicus var. japonicus ura-106

$S$. pombe his7-366 $h^{+} \times S$. japonicus var. japonicus ura-110

$S$. pombe his7-366 $h^{-} \times S$. japonicus var. versatilis lys-103

$S$. pombe his7-366 $h^{-} \times S$. japonicus var. versatilis glu-126

$S$. pombe his7-366 $h^{+} \times S$. japonicus var. versatilis glu-126

$S$. pombe his7-366 $h^{+} \times S$. japonicus var. versatilis lys-103

$S$. malidevorans ura-103 $\times$ S. octosporus met-105

S. malidevorans ura-103 $\times$ S. octosporus ade- 110

$S$. malidevorans arg- $121 \times S$. octosporus met-105

$S$. malidevorans arg-121 $\times$ S. octosporus ade-110

$S$. malidevorans ura-103 $\times S$. japonicus var. japonicus ura-106

$S$. malidevorans ura-103 $\times S$. japonicus var. japonicus ura-110

$S$. malidevorans arg-121 $\times S$. japonicus var. japonicus ura-106

$S$. malidevorans arg-121 $\times S$. japonicus var. japonicus ura-110

$S$. malidevorans ura-103 $\times$ S. japonicus var. versatilis lys-103

$S$. malidevorans ura-103 $\times S$. japonicus var. versatilis glu-126

$S$. malidevorans arg-121 $\times$ S. japonicus var. versatilis lys-103

$S$. malidevorans arg-121 $\times$ S. japonicus var. versatilis glu-126

$S$. octosporus met-105 $\times S$. japonicus var. japonicus ura-106

$S$. octosporus met-105 $\times S$. japonicus var. japonicus ura-110

$S$. octosporus ade-110 $\times S$. japonicus var. japonicus ura-106

$S$. octosporus ade-110 $\times S$. japonicus var. japonicus ura-110

S. octosporus met-105 $\times$ S. japonicus var. versatilis lys -103

$S$. octosporus met-105 $\times S$. japonicus var. versatilis glu-126

$S$. octosporus ade-110 $\times S$. japonicus var. versatilis lys-103

$S$. octosporus ade-110 $\times S$. japonicus var. versatilis glu- 126

$S$. japonicus var. japonicus ura-106 $\times$ S. japonicus var. versatilis lys-103

$S$. japonicus var. japonicus ura-106 $\times S$. japonicus var. versatilis glu-126

$S$. japonicus var. japonicus ura-110 $\times$ S. japonicus var. versatilis lys-103

$S$. japonicus var. japonicus ura-110 $\times$ S. japonicus var. versatilis glu-126
$10 \cdot 7$

47.0

37.0

37.6

36.4

$22 \cdot 7$

26.3

$19 \cdot 1$

$31 \cdot 0$

$17 \cdot 0$

26.8

22.9

$19 \cdot 9$

$15 \cdot 3$

$17 \cdot 2$

$20 \cdot 5$

19.7

$21 \cdot 6$

24. 0

19.5

$22 \cdot 2$

$26 \cdot 3$

$31 \cdot 2$

$62 \cdot 3$

$47 \cdot 4$

32.9

21.0

$28 \cdot 3$

$34 \cdot 1$

$7 \cdot 3$

$10 \cdot 7$

3.9

$11 \cdot 2$

14.6

8.9

$11 \cdot 6$

9.9

$10 \cdot 5$

$10 \cdot 2$

$18 \cdot 0$

6.1

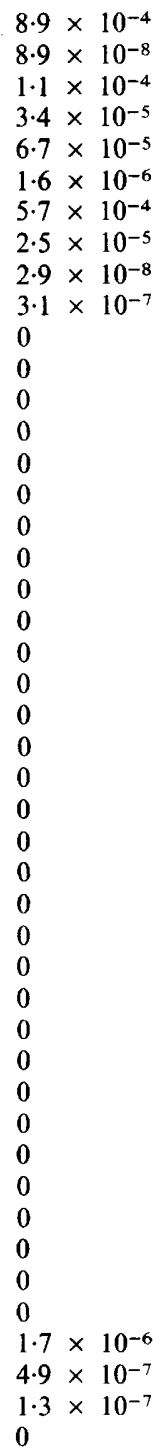

haploid spores. In crosses of $S$. octosporus and $S$. japonicus no similar conclusion could be drawn because of their less regular cell shape and size.

\section{Interspecific crosses involving auxotrophic mutants}

In order to detect interfertility between species, at least two mutants per species were massmated in all possible combinations, and tested for production of prototrophs. Data relating to the individual crossings are given in Table 2 . Colonies arose only from crosses between $S$. pombe 
and $S$. malidevorans. Their frequencies ranged from $2.9 \times 10^{-8}$ to $5.7 \times 10^{-4}$. No prototrophs (that is no interfertility) were detected in the other combinations.

To return to the crosses between $S$. pombe and to $S$. malidevorans, it is worth noting that the prototroph frequency depends to a great extent on the mating type of the $S$. pombe partner. If strains of $h^{-}$type were involved, the frequency was nearly as high as in the intraspecific $h^{-} \times h^{+}$ cross. In the combinations $S$. pombe his 7-366 $h^{+} \times S$. malidevorans ura-103 and $S$. pombe his $7-366 h^{+} \times S$. malidevorans arg-121, the prototroph frequency remained at a level three orders of magnitude lower. These differences suggest that the $S$. malidevorans mutants used are presumably of a heterothallic mating type resembling the $h^{+}$type of $S$. pombe. The average percentage of colonies with increased cell size was $43.94 \%$ when $h^{-}$was crossed with $S$. malidevorans. Since most of these sporulated on MEA and formed azygotic asci (Leupold, 1970), they can be regarded as 'interspecific' diploids.

No significant differences were found between the prototroph frequencies of samples taken at various time intervals. The data in Table 2 depict only the situation after the fourth passage.

Twenty prototrophic colonies presumed to be diploid were isolated from the MMA plates and examined for maltose fermentation. All of them could utilize maltose fermentatively, which strongly indicates that their genotype was $\mathrm{mal}^{-} / \mathrm{mal}^{+}$and that the mal ${ }^{+}$character was dominant. Since the taxonomic distinction between these species is based mainly on their different abilities to ferment maltose ( $S$. pombe is $\mathrm{mal}^{+}$, while $S$. malidevorans is $\mathrm{mal}^{-}$), the further fate of $\mathrm{mal}^{+}$ during sporulation of hybrids was also of great interest. To study its segregation, a strain of $S$. pombe carrying markers in all chromosomes was constructed and crossed with $S$. malidevorans ura-103. The $S$. pombe his7-366 arg-1 leu2-120 $h^{-}$partner carried the leu-2, his-7 and arg-1 markers on chromosomes I, II and III, respectively (Kohli et al., 1977), and in addition possessed the $\mathrm{mal}^{+}$allele. The $S$. malidevorans was known to have the ura marker and the malcharacter, but both in unknown positions. A prototrophic diploid hybrid was picked off and sporulated, and a random analysis of the spores was carried out. Colonies (298) arising from haploid spores were isolated and characterized for auxotrophy as well as for maltose fermentation. The results are summarized in Table 3. (Data on wild-type colonies are not given, because it was difficult to judge which ones originated from spores.) The following conclusions can be drawn from the results. (i) The hybrid studied must have been diploid, because all markers involved could be reisolated. (ii) During meiosis and spore formation the chromosomes of both parents showed independent reassortment, which is expressed in the nearly equal frequencies of single and double auxotrophs. (iii) The mal' character is very probably linked to leu-2. Consequently, the mal gene for $S$. pombe is located in chromosome I. (iv) Recombination took place within two chromosomes, as can be inferred from the segregation of markers in chromosome I (leu-2 and $\mathrm{mal}^{+}$) and chromosome II ( $h i s-7$ and $h^{-}$).

For a more precise localization of $\mathrm{mal}$ in chromosome I the above-mentioned cross was repeated and asci were isolated. However, tetrad analysis was not possible, because of the low viability of the spores: no complete tetrad was found among 50 asci dissected. The presumable reason for the low proportion of viable spores is the physiological differences between the parents. With the intention of reducing their influence in subsequent crosses, a new partner was chosen for $S$. pombe. This was a segregant spore designated 179 his7-366 arg-1 ura mal $^{-}$from the cross discussed above. As regards the genotype, it was thought to have two chromosomes (carrying his-7 and arg-1) from $S$. pombe and the remaining part of its genome (carrying ura) from $S$. malidevorans. Since the mating character of $S$. malidevorans was also retained, this strain could be crossed with $S$. pombe his7-366 arg-1 leu2-120 h- However, the viability of the spores was not higher in this case either, and so the tetrad analysis again proved impossible. Nevertheless, segregation of $\mathrm{mal}^{+}$character in the viable spores allowed certain inferences concerning the localization of the mal gene. Leaving aside the his-7 and arg- 1 markers, of 910 spores isolated 254 were prototrophs, 224 were leu ura, 212 were ura and 220 were leu. The nearly equal numbers of the four types, characteristic of zygotes heterozygous for two markers, favours the supposition that none of the spore classes exhibited any differential viability. The leucine auxotrophic spores were also tested for maltose fermentation, and it turned out that $94 \%$ of them were mal ${ }^{+}$. Hence, $\mathrm{mal}^{+}$and leu-2 are probably closely linked. 


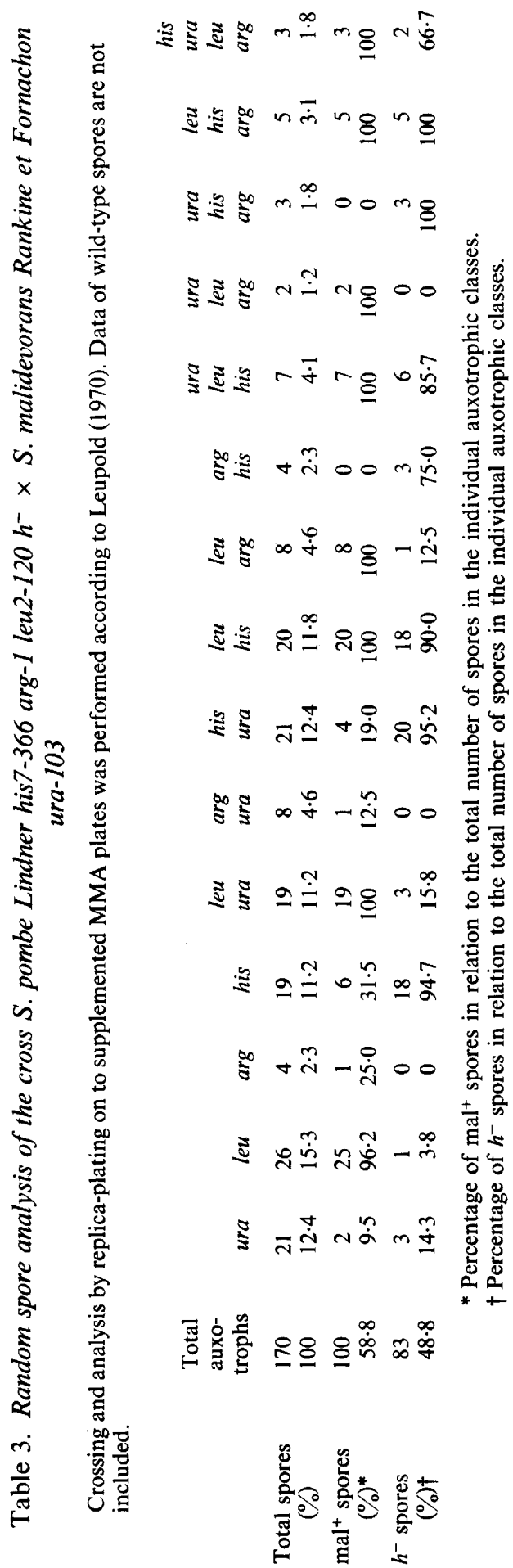




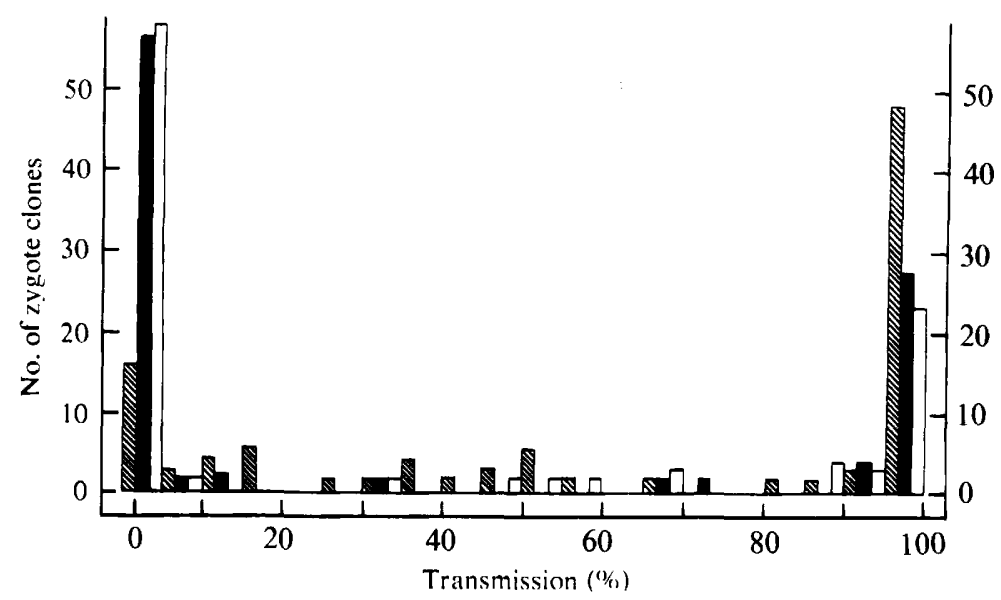

Fig. 1. Transmissional pattern of mitochondrial markers in 100 individual zygote clones from the cross $S$. pombe lys4-95 diur -301 ery ${ }^{r}-100 h^{-} \times S$. malidevorans ura-103. Crossing and isolation of diploid clones were carried out as described in the Methods. Cells of diploid clones were spread on to MMA plates and resistance of the colonies appearing was determined by replica-plating on to GCM plates supplemented with the respective drugs. The transmissional pattern is plotted in intervals of $5 \%$ transmission of $d_{i u}^{r}$, ery ${ }^{r}$ and double resistance. $\square$, diu ${ }^{r}$-transmission; ery $y^{r}$-transmission; $\square, d i u^{r} e r y^{\Gamma_{-}}$ transmission.

\section{Transmission of mitochondrial genomes in zygote clones from a cross of $S$. pombe $\times$ $S$. malidevorans}

Cells of $S$. pombe lys 4-95 diur $-301 e r y^{r}-100 h^{-}$conferring mitochondrially inherited resistance to diuron [3(3,4-dichlorophenyl)-1,1-dimethylurea] and erythromycin were mass-mated with cells of $S$. malidevorans ura-103. Zygotes were isolated as described in the Methods, resuspended individually and plated on MMA. Colonies appearing were then replica-plated on MMA supplemented with drugs. For each zygote clone about 200 colonies were analysed for resistance. Figure 1 shows the transmissional pattern of 100 individual zygote clones, plotted in intervals of $5 \%$ transmission of diu $^{\mathrm{r}}$, ery ${ }^{\mathrm{r}}$ and double resistance. Most of the clones belonged to the classes of $0-5 \%$ and $95-100 \%$ resistance transmission and very few consisted of cells of different phenotypes. Erythromycin resistance was transmitted more frequently than diuron resistance and only a comparatively low proportion of clones showed double resistance. The excess of $\operatorname{ery}^{\mathrm{r}}$ and $d i u^{\mathrm{r}}$ over the parental ery $\mathrm{r}^{\mathrm{r}}$ diu $\mathrm{r}$ phenotype indicates that frequent recombinations occurred between mitochondria of $S$. pombe and $S$. malidevorans during copulation and/or multiplication of the zygotes.

\section{Somatic hybridization by protoplast fusion}

Cells of auxotrophic strains used for crosses and listed in Table 2 were converted into protoplasts by use of a lytic enzyme produced by Trichoderma viride. Protoplasts were mixed in all possible combinations, fused using PEG, and prototrophic fusion products were selected on MMAK. After $14 \mathrm{~d}$ the resulting fusion colonies were counted, and their frequencies compared to the total number of protoplast pairs used were calculated. In all intraspecific combinations, prototrophs occurred with frequencies comparable to those observed in crosses. As expected, the same was found between $S$. pombe and $S$. malidevorans. In addition, however, slowly growing colonies were also formed when $S$. malidevorans or $S$. pombe was fused with $S$. octosporus (Table 4). In principle, their morphology and segregation were similar to those described in a previous paper (Sipiczki, 1969).

\section{Low-temperature absorption spectra of Schizosaccharomyces species}

Low-temperature spectra of the cellular cytochromes of Schizosaccharomyces species are shown in Fig. 2. For better analysis a wild-type DP1-1D strain of Saccharomyces cerevisiae which 
Table 4. Frequencies of prototrophic colony formation between $S$. pombe, $S$. malidevorans and $S$. octosporus auxotrophic mutants after PEG-induced protoplast fusion

Protoplasts were prepared, mixed, treated with PEG and plated on to MMAK as described in Methods. The plates were incubated at $30^{\circ} \mathrm{C}$.

$$
\text { Strains fused } \quad \text { Fusion frequency }
$$

S. pombe Lindner his $7-366 h^{-} \times$

S. octosporus Beijerinck ade-110

S. pombe Lindner his7-366 $h^{+} \times$

$S$. octosporus Beijerinck ade-110

$S$. malidevorans Rankine et Fornachon ura-103 $\times$

S. octosporus Beijerinck ade-110

$S$. malidevorans Rankine et Fornachon arg-121 $\times$

S. octosporus Beijerinck ade-110

$$
\begin{aligned}
& 2.28 \times 10^{-4} \\
& 5.19 \times 10^{-5} \\
& 1.07 \times 10^{-5} \\
& 8.71 \times 10^{-5}
\end{aligned}
$$

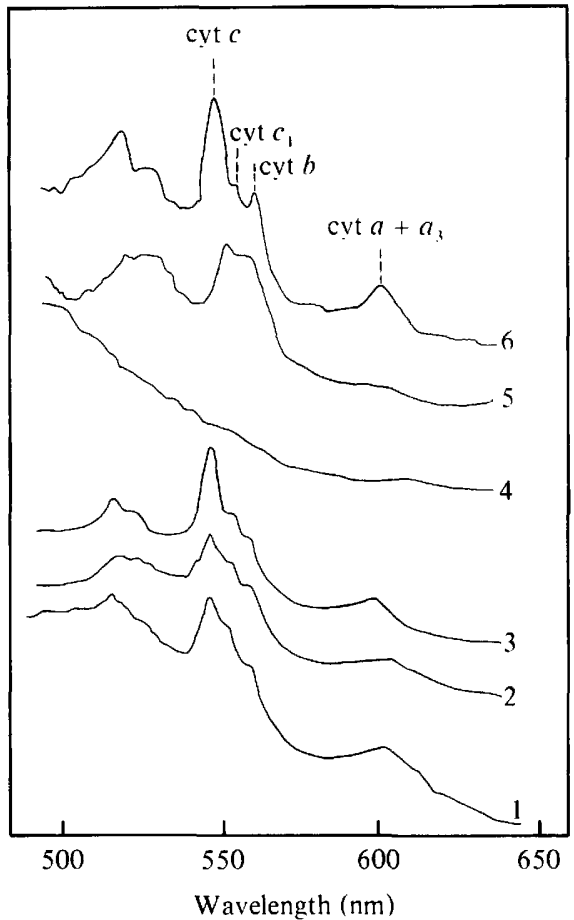

Fig. 2. Low-temperature spectra of aerobically grown cells of Schizosaccharomyces species and Saccharomyces cerevisiae. Cells were collected after $72 \mathrm{~h}$ aerobic growth at $28^{\circ} \mathrm{C}$ on YPG plates. Spectra were determined on $\mathrm{Na}_{2} \mathrm{~S}_{2} \mathrm{O}_{4}$-reduced whole cell pastes $1 \mathrm{~mm}$ thick versus neutral filter. Samples were chilled in liquid nitrogen. $1, S$. pombe Lindner his 7-366 $h^{-} ; 2, S$. octosporus Beijerinck CCY 44-2-1;3, $S$. malidevorans Rankine et Fornachon CCY 44-6-1 ; 4, S. japonicus var. versatilis (Wickerham et Duprat) Sloof CCY 44-3-1 (ATCC 9987); 5, S. japonicus var. japonicus Yukawa et Maki CCY 44-5-1 (CBS 354); 6, Saccharomyces cerevisiae DP1-1D.

contains cytochromes $a+a_{3}, b, c_{1}$ and $c$ was compared with them. The strains of $S$. pombe, $S$. malidevorans and $S$. octosporus contained all cytochromes, but in reduced amounts. Unexpectedly, $S$. japonicus var. versatilis lacked all cytochromes $a+a_{3}, b, c_{1}$ and $c$. In the case of the respiratory chain of $S$. japonicus var. japonicus cytochromes $a+a_{3}$ and $c$ were absent, as deduced from the lack of peaks for cytochrome $c$ in the $\alpha(548 \mathrm{~nm})$ and $\beta(520 \mathrm{~nm})$ regions and for cytochromes $a+a_{3}$ at $607 \mathrm{~nm}$. Finally, a close correlation was found between the absence of these cytochromes and the ability to grow on unfermentable carbon sources. Thus, strains of $S$. japonicus var. versatilis and $S$. japonicus var. japonicus which lack cytochromes $a+a_{3}$ and $c$, or $a$ $+a_{3}, b_{1}, c_{1}$ and $c$ are unable to grow on medium containing glycerol as the sole source of energy. 
The data in Table 2 demonstrate that prototrophs appeared in all intraspecific crosses, including those between $S$. japonicus var. japonicus and $S$. japonicus var. versatilis, with a frequency in the range $2.9 \times 10^{-8}-8.9 \times 10^{-4}$. One might attribute the marked differences in frequency to the different mating abilities of the species. Although this supposition must be correct to a certain extent, it has to be taken into account that formation of prototrophs can be affected by a number of factors which have nothing to do with the mating potency. Schizosaccharomyces has a haplontic life cycle (Leupold, 1950; Sloof, 1970), i.e. copulation is followed immediately by meiosis and haploid spores are formed within the cell wall of the original zygote (zygotic asci). However, zygotes can sometimes germinate into diploid cell clones which are distinguishable from haploids because they have larger cells, are unstable and form azygotic asci on sporulation medium; this is known in $S$. pombe (Leupold, 1970). Since the latter phenomenon is rather rare, the number of prototrophs in a mass combination of complementing auxotrophic mutants does not necessarily reflect the proportion of zygotes. All viable diploids form colonies on the selection medium, but only those spores do so which are recombinant. Since recombination leading to prototrophy is dependent upon the degree of linkage between the genes involved (Perkins, 1953), the number of prototrophic spores in mass-mated population is proportional to the degree of linkage of the markers used as well as to the number of zygotes. To avoid the effect of linkage, the interspecific crosses in $S$. pombe were made with strains carrying unlinked markers. The big differences between the frequencies were therefore due virtually only to the different mating type combinations.

A problem which may be encountered is that the growth rate of zygotes and/or recombinants can differ from that of the parents, whereby the proportion of prototrophs in a sample does not reflect the frequency of zygote formation. Of course, failure to detect prototrophs can also be due to the reduced fertility of the mutants used or to unfavourable combinations of mating types (e.g. both parents are of like mating types). In view of all these eventualities in Schizosaccharomyces it seems inadvisible, in contrast to Johanssen's (1980) suggestion for Kluyveromyces, to accept any arbitrary minimal recombinant rate as a criterion of the genetic relatedness of the parents.

Only $S$. pombe and $S$. malidevorans proved interfertile in interspecific crosses (Table 2). Although all species except $S$. pombe were presumed to be homothallic (Sloof, 1970; Wickerham \& Duprat, 1945; Beijerinck, 1894), both $h^{-}$and $h^{+}$strains of $S$. pombe were used in these experiments to avoid the possible influence of mating types. This precaution proved to be justified, because $S$. malidevorans showed a higher prototroph frequency with $h^{-}$than with $h^{+}$. It can therefore be assumed that $S$. malidevorans too is heterothallic, and its mutants were of a mating type resembling $h^{+}$of $S$. pombe. This finding is in disagreement with the report of Sloof (1970), who presumed the homothallism of this species.

Crossing of $S$. malidevorans with a $S$. pombe strain carrying markers in every chromosome enabled us to analyse the recombination of nuclear genes. It is evident from the results in Table 3 that chromosomes of both parents segregated independently and recombination also took place within two chromosomes. These data, together with those revealing recombination between mitochondrial genomes, suggest the strong genetic relatedness of $S$. pombe and $S$. malidevorans. Since this may give rise to more or less free exchanges of genes in their mixed populations, they can not be considered as distinct species. The considerable similarity of their respiratory chains, suggested by the cytochrome spectra, also supports this conclusion.

Johannsen (1981) recently reported hybridization studies within the genus Schizosaccharomyces, but she failed to recover recombinants or hybrids between the species. The disagreement of her findings with ours is probably due to the fact that the $S$. pombe strains used in the crosses were of different origins. Johannsen's strains ( $S$. pombe Lindner CBS 5682 and CSIR Y 469) originated from the Yeast Collection of the Centraalbureau voor Schimmelcultures (CBS) or from the Council for Scientific and Industrial Research (CSIR), while our mutants were obtained from a genetic collection. It has to be stressed, however, that the original wildtype strain of the latter mutants [S. pombe Lindner str. liquefaciens (Osterwalder)] was also from CBS (Leupold, 1950).

Hybridization of $S$. pombe and an eight-spored species was attempted by Kossikov \& Medve- 
deva (1977). It is not clear, however, whether S. japonicus Yukawa et Maki [Octosporomyces japonicus (Yukawa et Maki) Kudriawzew] or S. octosporus Beijerinck [Octosporomyces octosporus (Beijerinck) Kudriawzew] was the partner of $S$. pombe: they used an adenine-requiring strain isolated from $S$. octosporus (Kossikhov \& Zapadnaya, 1974) but treated this strain as a mutant of Octosporomyces japonicus in the hybridization experiment. Nor was the hybrid, or recombinant, nature of the prototrophs recovered proved beyond doubt: the confirmation was based primarily on the morphological characteristics, without reference to the fermentation of melibiose and without the exclusion of genetic reversion to leaky forms.

By means of protoplast fusion further information could be obtained about the relatedness of the taxa. As shown in Table 4, prototrophic somatic hybrids were formed between the fourspored strains and $S$. octosporus. Although the fusion products were not stable and possessed a disturbed genetic balance reflected in low viability, formation of incomplete cell wall, and osmotic sensitivity (Sipiczki, 1979), the two genomes could nevertheless exist together, which is taken as good evidence of their close relatedness. As such hybrids could be constructed and maintained only under laboratory conditions, the fusion partners still have to be regarded as separate species.

The results reported in this work show that a revision of the genus is required. Being interfertile, $S$. pombe Lindner and $S$. malidevorans Rankine et Fornachon have to be included in one species. As regards Art. 57 of the International Code of Botanical Nomenclature (Stafleu et al., 1972), the oldest legitimate descriptive expression, i.e. the term pombe introduced by Lindner (1893), has to be retained for this new species. In spite of the interfertility, there are still a number of morphological and physiological differences, such as a rough outer membrane on the spores of $S$. malidevorans, its inability to ferment maltose, and its increased ability to decompose L-malic acid and to produce hydrogen sulphide (Rankine \& Fornachon, 1964), which all offer a possibility to distinguish these two taxa. It therefore seems justified to relegate them [in terms of Art. 60 of the International Code of Botanical Nomenclature (Stafleu et al., 1972)] to the status of two varieties of Schizosaccharomyces pombe Lindner as follows:

1. Schizosaccharomyces pombe Lindner var. pombe; synonym, Schizosaccharomyces pombe Lindner (1893).

2. Schizosaccharomyces pombe Lindner var. malidevorans; synonym, Schizosaccharomyces malidevorans Rankine et Fornachon (1964).

To legalize the proposed taxonomical situation the authors give the following descriptions.

Schizosaccharomyces Lindner 1893. emend.

Genus of the class Endomycetes of Fungi. Mononucleate, rectangular box-shaped or cylindric cells with rounded ends multiplying by 'fission' (annelloconidiogenesis on a broad basis at both ends of the cell); occurrence of true mycelium was observed. Cell wall consists of galactomannans, $\alpha$-glucans and $\beta$-glucans; chitin is absent. Extracellular polysaccharides staining blue with iodine may occur. Homothallic or heterothallic conjugation of two vegetative cells, one vegetative cell and spore or two spores produce zygote in which after meiotic division (2)-4-8 globose, rectangular box-shaped or reniform spores are produced. Spore wall is smooth or verrucose. Vegetative multiplication of the zygotes by fission may occur; diploid cells form spores without previous conjugation. Fermentation and assimilation of some sugars and assimilation of inulin and glycerol was observed. During utilization of sugars a more or less intensive decomposition of malic acid into carbon dioxide and ethanol may occur. Assimilation of nitrates is negative. Inositol as growth factor is always needed. Coenzyme $\mathrm{Q}$ is of the $\mathrm{CoQ}_{10}$ or of the $\mathrm{CoQ}_{9}$ type. Type species: Schizosaccharomyces pombe Lindner.

Genus Fungorum de classe Endomycetes. Cellulae uninucleate, oblongae aut cylindricae obtusae multiplicantes per 'fissionem': processus qui est annelloconidiogenesis performatus ad ambos extremibus cellulae cum base lata. Productio mycelii veri accidere potest. Paries cellulae constat ex galactomannanis, $\alpha$-glucanis $\beta$-glucanisque; quitinum abest. Productio extracellularis compositorum amylo similium adest. Zygota formatur per conjugationem heterothallicam aut homothallicam duae cellulae vegetativae, unae cellulae et unae sporae aut duae sporae. In zygota per divisionem meioticam (2)-4-8 sporae globosae, oblongae vel reniformes formantur. Paries sporae levis aut verrucosus. Multiplicatio vegetativa zygotae per fissionem accadit; in cellulis 
diploidois sporae formantur sine coniguatione precedente. Fermentatio assimilatioque aliquorum saccharorum, casu assimilatio inulini et glyceroli. Tempore utilisationis saccharorum decompositio plus minusve fortis acidi malici in dioxido carboni et ethanolo. Assimilatio nitratis negativa. Inositolum ad multiplicationem semper necessarium. Coenzymum $Q$ est de typo $\mathrm{CoQ}_{10}$ vel $\mathrm{CoQ}_{9}$. Species typica: Schizosaccharomyces pombe Lindner.

Schizosaccharomyces pombe Lindner 1893. emend.

Species of the genus Schizosaccharomyces. Assimilates glucose, sucrose and raffinose. Assimilation of maltose, $\alpha$-Me-glucoside, inulin and glycerol variable. Ferments glucose and sucrose; fermentation of maltose and raffinose variable. Coenzyme $Q$ is of the $\mathrm{CoQ}_{10}$ type.

Species generis Schizosaccharomyces. Assimilat glucosum, saccharosum et raffinosum. Assimilatio maltosi, $\alpha$-Me-glucosidi, inulini et glycerol variabilis. Fermentat glucosum et saccharosum; fermentatio maltosi et raffinosi variabilis. Coenzymum $Q$ est de typo $\mathrm{CoQ}_{10}$.

Schizosaccharomyces pombe Lindner var. pombe

Variety of the species Schizosaccharomyces pombe. Assimilates glucose, sucrose, maltose and raffinose; assimilation of $\alpha$-Me-glucoside, inulin and glycerol variable. Ferments glucose, sucrose and maltose. At $37^{\circ} \mathrm{C}$ growth occurs. Type strain: CBS 356.

Varietas speciei Schizosaccharomyces pombe. Assimilat glucosum, saccharosum, maltosum et raffinosum; assimilatio $\alpha$-Me-glucosidi, inulini et glyceroli variabilis. Fermentat glucosum, saccharosum et maltosum. Multiplicat ad $37^{\circ} \mathrm{C}$. Cultura typica: CBS 356 .

Schizosaccharomyces pombe Lindner var. malidevorans Rankine et Fornachon (1964)

Variety of the species Schizosaccharomyces pombe. Assimilates and ferments glucose, sucrose and raffinose; assimilation of inulin variable; assimilation of maltose, $\alpha$-Me-glucoside and glycerol negative. No growth at $37^{\circ} \mathrm{C}$. Type strain: CBS 5557.

Varietas speciei Schizosaccharomyces pombe. Assimilat et fermentat glucosum, saccharosum et raffinosum; assimilatio inulini variabilis; assimilatio maltosi, $\alpha$-Me-glucosidi et glyceroli negativa. Non multiplicat ad $37^{\circ} \mathrm{C}$. Culture typica: CBS 5557.

The results obtained in this work are in good agreement with the proposal of Yamada et al. (1973) that the two four-spored species should be included in one species. They were led to this conclusion by their findings on the coenzyme $Q$ systems of 16 strains. It was found that the fourspored pombe-malidevorans group possessed the $\mathrm{CoQ}_{10}$ system, while the eight-spored octosporus-japonicus group was characterized by the $\mathrm{CoQ}_{9}$ system. The introduction of a new genus, Octosporomyces, suggested by Kudriawzew (1960) and supported by Yamada et al. (1973), which would include $S$. japonicus and $S$. octosporus, seems unjustified, however, especially in view of the ability of the latter to undergo somatic hybridization both with $S$. pombe and with $S$. malidevorans and the strong similarities of its cytochrome spectra to those of the four-spored group (Fig. 2 and Claisse \& Simon-Becam, 1978). The homogeneity of the genus is supported by the results of Spencer \& Gorin (1969), who reported that the proton magnetic resonance spectra of the cell wall galactomannans of the four species were very similar. Nevertheless, a detailed DNA-DNA reassociation analysis of nucleic acid homologies would be of great help in further revealing the degrees of relatedness between the taxa of this genus. GC (guanine and cytosine) contents of DNA so far published, $40-44.8 \%$ and $42 \%$ for $S$. pombe and $S$. octosporus, respectively (Rose \& Venner, 1964; Storck, 1966) do not allow a reliable conclusion.

We are most grateful to Dr A. Kocková-Kratochvilová, Professor U. Leupold and Dr K. Wolf who have supplied us with strains. We thank Professor L. Ferenczy and Dr E. K. Novák for helpful advice and constructive opinions and Erzsébet Juhász for excellent technical assistance.

\section{REFERENCES}

BEIJERINCK, M. W. (1894). Schizosaccharomyces octosporus, eine achtsporige Alkoholhefe. Zentralblatt für Bakteriologie und Parasitenkunde 16, 49-58.

Claisse, M. L. \& Simon-Becam, A.-M. (1978). Cytochrome $c$ from Schizosaccharomyces pombe. I. Purification, spectral properties and amino-acid composition. European Journal of Biochemistry 86, 399-406.

EGEL; R. (1976). The genetic instabilities of the mating type locus in fission yeast. Molecular and General Genetics 145, 281-286.

JOHANNSEN, E. (1980). Hybridization studies within 
the genus Kluyveromyces van der Walt. Antonie van Leeuwenhoek 40, 177-189.

JOHANNSEN, E. (1981). Hybridization within the genus Schizosaccharomyces Lindner. Canadian Journal of Microbiology 27, 184-191.

JOHANNSEN, E. \& VAN DER WALT, J. P. (1978). Interfertility as bases for the delimitation of Kluyveromyces marxianus. Archives of Microbiology 118, 4548.

Kohli, J., Hottinger, H., Munz, P., Strauss, A. \& ThuriauX, P. (1977). Genetic mapping in Schizosaccharomyces pombe by mitotic and meiotic analysis and induced haploidization. Genetics 87, 471-489.

Kossikhov, K. V. \& ZapadnaYa, A. A. (1974). UVinduction of adenine-dependent mutants in Schizosaccharomyces octosporus. Genetika 10 (6), 89-93 (in Russian).

Kossikov, K. V. \& Medvedeva, A. A. (1977). Isolation of hybrids of Schizosaccharomyces pombe and Octosporomyces japonicus. Mikrobiologiya 46, 61-65 (in Russian).

KUDRIAWZEW, W. I. (1960). Die Systematik der Hefen. Berlin: Akademie-Verlag.

KUMBHOJXAR, M. S. (1972). Schizosaccharomyces sloofi Kumbhojkar, a new species of osmophilic yeast from India. Current Science 41, 151-152.

LEUPOLD, U. (1950). Die Vererbung von Homothallie und Heterothallie bei Schizosaccharomyces pombe. Comptes rendus des travaux du Laboratoire Carlsberg, Série Physiologique 24, 381-480.

LEUPOLD, U. (1956). Some data on polyploid inheritance in Schizosaccharomyces pombe. Comptes rendus des travaux du Laboratoire Carlsberg, Série Physiologique 26, 211-251.

LEUPOLD, U. (1970). Genetic methods for Schizosaccharomyces pombe. Methods in Cell Physiology 4, 169-177.

LINDNER, P. (1893). Schizosaccharomyces pombe n.sp., neuer Gärungserreger. Wochenschrift für Brauerei 10, 1298.

LoDder, J. (1970). The Yeasts. A Taxonomic Study, Amsterdam: North-Holland Publishing Co.

NeumanN, I. (1972). Biotaxonomische und systematische Untersuchungen an einigen Hefen der Gattung Saccharomyces. Beihefte zur Nova Hedwigia $\mathbf{4 0}$, $1-79$.

PERkins, D. D. (1953). The detection of linkage in tetrad analysis. Genetics 38, 187-197.

RANKINE, B. C. \& ForNACHON, J. C. M. (1964). Schizosaccharomyces malidevorans $\mathrm{sp}$. $\mathrm{n}$., a yeast decomposing L-malic acid. Antonie van Leeuwenhoek 30, 73-75.

RosT, K. \& VENNER, H. (1964). Untersuchung an Nucleinsäuren. $\mathrm{X}$. Isolierung und Untersuchung von Desoxyribonucleinsäure aus Hefen. Zeitschrift für Physiologische Chemie 339, 230-237.

SeItZ-MaYR, G., Wolf, K. \& Kaudewitz, F. (1978). Extrachromosomal inheritance in Schizosaccharomyces pombe. VII. Studies by zygote clone analysis on transmission, segregation, recombination and uniparental inheritance of mitochondrial markers conferring resistance to antimycin, chloramphenicol and erythromycin. Molecular and General Genetics 164, 309-320.

SIPICZKI, M. (1979). Interspecific protoplast fusion in fission yeasts. Current Microbiology 3, 37-40.
SiPICZKI, M. \& FerenCzy, L. (1977). Protoplast fusion of Schizosaccharomyces pombe auxotrophic mutants of identical mating-type. Molecular and General Genetics 151, 78-81.

SIPICZKI, M. \& FERENCZY, L. (1978). Enzymic methods for enrichment of fungal mutants. I. Enrichment of Schizosaccharomyces pombe mutants. Mutation Research 50, 163-173.

SLOOF, W. C. (1970). The genus Schizosaccharomyces Lindner. In The Yeast. A Taxonomic Study, pp. 733755. Edited by J. Lodder. Amsterdam: North-Holland Publishing Co.

SPENCER, J. F. T. \& Gorin, P. A. J. (1969). Systematics of the genera Saccharomyces, Schizosaccharomyces, Endomycopsis, Kluyveromyces, Schwanniomyces and Brettanomyces: proton magnetic resonance spectra of the mannans and mannose-containing polysaccharides as an aid in classification. Antonie van Leeuwenhoek 35, 361-378.

Stafleu, F. A., Bonner, C. E. B., McVaugh, R., MeIkle, R. D., Rollins, R. C., Ross, R., SCHOPF, J. M., Schiwlze, G. M., DE Vilmorin, R. \& Voss, E. G. (1972). International Code of Botanical Nomenclature. Adapted by the Eleventh International Botanical Congress, Seattle, August $1969 . \quad$ Utrecht: A. Oosthoek's Uitgeversmaatschappij N.V.

STAHL, U. \& ESSER, K. (1979). Inconsistency in the species concept for yeasts due to mutations during vegetative growth. European Journal of Applied Microbiology and Biotechnology 8, 271-278.

STORCK, R. (1966). Nucleotide composition of nucleic acids of fungi. II. Deoxyribonucleic acids. Journal of Bacteriology 91, 227-230.

Suminoe, K. \& Dukmo, H. (1963). The life cycles of Schizosaccharomyces with reference to the mode of conjugation and ascospore formation. Journal of General and Applied Microbiology 9, 243-247.

WALT, VAN DER, J. (1970). Criteria and methods used in classification. In The Yeasts. A Taxonomic Study, pp. 34-113. Edited by J. Lodder. Amsterdam: NorthHolland Publishing Co.

Wickerham, L. (1970). The genus Hansenula H. et P. Sydow. In The Yeasts. A Taxonomic Study, pp. 226315. Edited by J. Lodder. Amsterdam: North-Holland Publishing Co.

Wickerham, L. J. \& Burton, K. A. (1956). Hybridization studies involving Saccharomyces lactis and $Z y$ gosaccharomyces ashbyii. Journal of Bacteriology 71, 290-295.

Wickerham, L. J. \& Duprat, E. (1945). A remarkable fission yeast, Schizosaccharomyces versatilis nov. sp. Journal of Bacteriology 50, 597-607.

Winge, Ö. \& LAUSTSEN, O. (1939). On 14 new yeast types, produced by hybridization. Comptes rendus des travaux du Laboratoire Carlsberg, Série Physiologique 22, 337-352.

Wolf, K., Sebald-Althaus, M., Schweyen, R. J. \& KaUdEwITZ, F. (1971). Respiration deficient mutants of Schizosaccharomyces pombe. I. Molecular and General Genetics 110, 101-109.

YAMADA, Y., ARImoto, M. \& Kondo, K. (1973). Coenzyme $Q$ system in the classification of the ascosporogeneous yeast genus Schizosaccharomyces and yeastlike genus Endomyces. Journal of General and Applied Microbiology 19, 353-358. 